\title{
Nanoscale dissolution and growth on anhydrite cleavage faces
}

\author{
Carlos M. Pina \\ Department of Crystallography and Mineralogy, Complutense University of Madrid, cl José Antonio Novais 2, Madrid E-28040, Spain
}

\begin{abstract}
In situ atomic force microscopy (AFM) was used to study the molecular-scale reactivity of anhydrite $\left(\begin{array}{lll}1 & 0 & 0\end{array}\right),\left(\begin{array}{lll}0 & 1 & 0\end{array}\right)$, and $\left(\begin{array}{ll}0 & 0\end{array}\right)$ faces exposed to water and $\mathrm{CaSO}_{4}$ aqueous solutions at room temperature. In pure water, dissolution occurs by step retreat and etch pit nucleation and growth. Both the kinetics of the step retreat and the shape of the etch pits are surface-specific and crystallographically controlled. In $\mathrm{CaSO}_{4}$ aqueous solutions with concentrations ranging from $0.030 \mathrm{~mol} / 1$ to $0.075 \mathrm{~mol} / 1$, the growth kinetics on anhydrite $\left(\begin{array}{lll}1 & 0 & 0\end{array}\right)$ and $\left(\begin{array}{lll}0 & 1 & 0\end{array}\right)$ faces was studied. Growth is also strongly controlled by crystallographic constraints and occurs exclusively from pre-existing step edges by highly anisotropic spreading of monolayers $\left(\sim 3.5 \AA\right.$ in height). The AFM observations demonstrate that monolayer growth can occur on anhydrite $\left(\begin{array}{llllll}0 & 1 & 0\end{array}\right)$ and $\left(\begin{array}{lll}1 & 0 & 0\end{array}\right)$ faces even from slightly supersaturated solutions. In addition, the comparison of the step kinetics on anhydrite faces shows that the mechanisms of step dissolution and growth are essentially the same, with the direction of migration of crystal building units being reversed at the anhydrite saturation point. Moreover, the analysis of both high resolution AFM images and lateral force microscopy (LFM) images confirms that the newly-formed monolayers are anhydrite growing in structural continuity with the original $\left(\begin{array}{lll}1 & 0 & 0\end{array}\right)$ and $\left(\begin{array}{lll}0 & 1 & 0\end{array}\right)$ surfaces. However, the formation of the first monolayers is metastable and two-dimensional nucleation and further multilayer growth of anhydrite are strongly inhibited even at high supersaturations.
\end{abstract}

\section{INTRODUCTION}

Anhydrite $\left(\mathrm{CaSO}_{4}, \mathrm{Amma}, a_{0}=7.006 \AA, b_{0}=6.998 \AA\right.$, $\left.c_{0}=6.245 \AA\right)$ and gypsum $\left(\mathrm{CaSO}_{4} \cdot 2 \mathrm{H}_{2} \mathrm{O}, I 2 / a, a_{0}=5.670\right.$ $\AA, b_{0}=15.201 \AA, c_{0}=6.533 \AA, \beta=118.6^{\circ}$ ) are key minerals linked to the global sulphur biogeochemical cycle (Cole and Lancucki, 1974; Kirfel and Will, 1980; Holland, 2004; Warren, 2005). Frequently, anhydrite and gypsum occur in association with sodium chloride and other soluble salts in evaporite deposits (Butler, 1969; Warren, 2005; Rouchy and Blanc-Valleron, 2006). A variety of experiments and calculations have indicated that anhydrite can only directly precipitate from pure $\mathrm{CaSO}_{4}$ aqueous solutions above temperatures ranging from $42^{\circ} \mathrm{C}$ (D'Ans, 1968) to $58^{\circ} \mathrm{C}$ (Hardie, 1967). At lower temperatures, gypsum precipitates instead of anhydrite. However, by increasing the salinity, the minimum temperature for anhydrite precipitation can be further lowered to about $18{ }^{\circ} \mathrm{C}$ for chloride brines that are saturated with

E-mail address: cmpina@geo.ucm.es respect to sodium chloride and gypsum (Hardie, 1967). In addition, the solubility of anhydrite increases as pressure increases, and decreases as temperature increases (Zen, 1965; Blount and Dickson, 1969; Moller, 1988; Messnaoui and Bounahmidi, 2006). The complex (and opposite) effects of solubility, salinity, temperature, and pressure on the anhydritegypsum precipitation boundary make it difficult to determine if anhydrite and gypsum found in many evaporite deposits precipitated primarily or if they formed secondarily by replacement reactions (Stewart, 1953; Conley and Bundy, 1959; Holliday, 1970; Shearman, 1983).

In nature, the formation of gypsum after anhydrite, i.e. the gypsification of anhydrite, is a frequent mineral replacement reaction (Bundy, 1956; Sanz-Rubio et al., 1999; Freyer and Voigt, 2003; García-Ruiz et al., 2007). Because of their applicability to many fields, such as engineering, and cement and plaster manufacturing, hydration-dehydration and dissolution-crystallisation reactions affecting anhydrite and gypsum have been studied for many decades (e.g. Ball and Norwood, 1969; Taylor and Baines, 1970; Liu and Nancollas, 1970; Kosztolanyi et al., 1987; Rull et al., 
1989; Putnis et al., 1990; Reimann, 1991; Sievert et al., 2005). Interaction of water with rocks containing anhydrite can lead to the total or partial conversion of this mineral into gypsum (Goldmann, 1952; Bath et al., 1987). According to Holliday (1970), there are three main processes through which secondary gypsum can form from anhydrite: (a) anhydrite dissolution followed by gypsum precipitation; (b) direct hydration of anhydrite, and (c) stepwise hydration of bassanite $\left(\mathrm{CaSO}_{4} 1 / 2 \mathrm{H}_{2} \mathbf{O}\right)$. In the case of the direct hydration of one mol of anhydrite into one mol of gypsum, the reaction leads to a volume increase of about $40 \%$. Such a volume increase has been frequently invoked to explain some instances of rock swelling that cause major geotechnical problems during the construction of, for example, railway tunnels (Alonso et al., 2005; Berdugo et al., 2006; Berdugo, 2007). However, the proposed direct or stepwise hydrations of anhydrite seem to be more theoretical chemical reactions than actual mechanisms of gypsification. In contrast, the replacement of anhydrite by gypsum by a coupled dissolution-crystallisation mechanism is a more plausible mechanism, at least on the Earth's surface, where solid-state reactions are kinetically hindered due to the low temperatures and pressures. In such a case, the gypsification might involve a number of processes at the surfacefluid interface (e.g. hydration, surface complexation, epitaxial growth, generation of porosity) that do not necessarily result in the expected volume increase (Reimann, 1991). Considering that the replacement of anhydrite by gypsum is essentially a surface process that involves the coupling of dissolution and crystallisation reactions, the mechanisms of gypsification can be adequately addressed by studying the properties and reactivity of anhydrite and gypsum surfaces that are in contact with aqueous solutions. In this context, the application of atomic force microscopy (AFM) to the study of anhydrite and gypsum surfaces can be very useful. This has been demonstrated by numerous recent studies that have provided new insights into the nanoscale dissolution, growth, and dehydration phenomena that occur in the $\mathrm{CaSO}_{4}-\mathrm{H}_{2}$ system (e.g. Shindo et al., 1992, 1996, 2001; Bosbach and Rammensee, 1994; Bosbach et al., 1996; Finot et al., 1997; Jordan and Astilleros, 2006).

The aim of this work is to contribute to a better understanding of the reactivity of anhydrite crystals by studying the interaction of anhydrite $(\bullet 1),(1 \bullet)$, and ( $1 \bullet \bullet)$ surfaces with water and $\mathrm{CaSO}_{4}$ aqueous solutions using in situ AFM. This was done by: (i) analysing the structural and symmetry constraints that control the nanoscale dissolution and growth behaviour on anhydrite faces; (ii) comparing the kinetics of dissolution and growth on anhydrite faces around the saturation state; and (iii) identifying the phase of the growth monolayers on the anhydrite $(10)$ and $(1 \bullet 0)$ faces from the structural information provided by both high resolution AFM images and lateral force microscopy (LFM) images.

\section{EXPERIMENTAL PROCEDURE}

\subsection{In situ atomic force microscopy (AFM) observations}

In situ nanoscale observations of dissolution and growth on anhydrite cleavage faces were carried out at room tem- perature in an AFM equipped with a fluid cell (Multimode, Vecco Instruments). AFM images were recorded in constant force mode while displaying both cantilever height and deflection signals. Silicon nitride tips (Veeco NP and NP-S) with a nominal force constant of $k=0.58 \mathrm{~N} / \mathrm{m}$ were used. Anhydrite crystals from Mexico were freshly cleaved parallel to $(1 \bullet \bullet),(\bullet)$, or $(\bullet 1)$ faces prior to each experiment. These cleavage surfaces were previously identified by their interference figures with an optical microscope (Nikon Labophot T2-Pol). In all cases, before injecting the $\mathrm{CaSO}_{4}$ solutions in the fluid cell of the AFM, deionised water was flowed over the crystal surfaces in order to study the dissolution behaviour of the anhydrite $(\bullet 1),(1)$, and $(1 \bullet)$ faces. $\mathrm{CaSO}_{4}$ solutions were then flowed over these anhydrite surfaces. Solutions were prepared by mixing $\mathrm{CaCl}_{2}$ and $\mathrm{Na}_{2} \mathrm{SO}_{4}$ solutions (SIGMA $99+\%)$. The $\mathrm{pH}$ of the solutions was measured with a pH-meter (Crison GLP21) immediately before injecting them into the fluid cell of the AFM. The supersaturations of the solutions with respect to gypsum, $\boldsymbol{\beta}_{\mathrm{gyp}}$, and anhydrite, $\boldsymbol{\beta}_{\mathrm{anh}}$, were calculated using the following expressions:

$\boldsymbol{\beta}_{\mathbf{z y p}}=\frac{a\left(\mathrm{Ca}^{2+}\right) \cdot a\left(\mathrm{SO}_{4}^{2}\right) \cdot a\left(\mathbf{H}_{2} \mathbf{O}\right)^{2}}{K_{\text {sp. } \mathbf{y p}}}$

$\boldsymbol{\beta}_{\mathrm{anh}}=\frac{a\left(\mathrm{Ca}^{2+}\right) \cdot a\left(\mathrm{SO}_{4}^{2}\right)}{K_{\text {sp, anh }}}$

where $a\left(\mathrm{Ca}^{2+}\right)$ and $a\left(\mathrm{SO}_{4}^{2}\right)$ are the activities of the $\mathrm{Ca}^{2+}$ and $\mathrm{SO}_{4}^{2}$ ions in the solution and $K_{\mathrm{sp}, \mathrm{gyp}}=10^{-4.58}$ and $K_{\text {sp anh }}=10^{-4.36}$ are the solubility products for gypsum and anhydrite at $25^{\circ} \mathrm{C}$, respectively (PHREEQC.DAT data base). The activity coefficients for the ions and water were calculated using the PHREEQC computer code and the PHREEQC.DAT data base (Parkhurst and Appelo, 2000). The calculations were conducted for $25^{\circ} \mathrm{C}$ and for the measured $\mathrm{pH}$ values of the solutions. Table 1 shows the composition, measured $\mathrm{pHs}$, ionic activities, and supersaturations with respect to gypsum and anhydrite of the solutions used in the AFM growth experiments. In all the cases the calculated water activity was $\sim 1$.

Monolayer growth rates on the anhydrite surfaces were determined from sequences of AFM deflection images obtained at scan rates which varied from $\sim 2$ to $\sim 10 \mathrm{~Hz}$ and 256 to 512 lines per scan. In order to minimise random errors, several runs of each experiment were conducted and velocities were measured for different steps for each run. For the solutions with the highest $\mathrm{CaSO}_{4}$ concentrations, homogeneous nucleation of gypsum occurs in the fluid cell of the AFM some minutes after starting the growth experiment. This leads to an undesirable decrease in the concentration of $\mathrm{CaSO}_{4}$ in the solution. In such cases, measurements of monolayer advancement were carried out in the first few minutes after preparing and injecting the solution into the fluid cell, and always before detecting gypsum nucleation.

\subsection{Lateral force microscopy (LFM) images}

A number of additional growth experiments were conducted in order to obtain structural information about 
Table 1

Concentrations, measured $\mathrm{pHs}$, iønic activities, and supersaturations with respect t॰ gypsum and anhydrite of the sølutions used in the AFM growth experiments.

\begin{tabular}{|c|c|c|c|c|c|c|c|c|}
\hline Solution number & {$\left[\mathrm{CaCl}_{2}\right](\mathrm{m} \bullet / \mathrm{l})$} & {$\left[\mathrm{Na}_{2} \mathrm{SO}_{4}\right](\mathrm{m \bullet l} / \mathrm{l})$} & $\mathrm{pH}$ & $a\left(\mathrm{Ca}^{2+}\right)$ & $a\left(\mathbf{S} \mathbf{O}_{4}^{2}\right)$ & $\boldsymbol{\beta}_{\mathrm{gyp}}$ & $\boldsymbol{\beta}_{\text {anh }}$ & Observations \\
\hline$\overline{1}$ & 0.020 & 0.020 & 5.87 & $5.71 \times 10^{-3}$ & $5.08 \times 10^{-3}$ & 1.10 & 0.66 & Dissølutiøn \\
\hline 2 & 0.025 & 0.025 & 5.84 & $6.62 \times 10^{-3}$ & $5.76 \times 10^{-3}$ & 1.45 & 0.87 & Slight diss@lutiøn \\
\hline 3 & 0.030 & 0.030 & 5.94 & $7.47 \times 10^{-3}$ & $6.37 \times 10^{-3}$ & 1.82 & 1.10 & Grøwth \\
\hline 4 & 0.035 & 0.035 & 5.90 & $8.28 \times 10^{-3}$ & $6.92 \times 10^{-3}$ & 2.19 & 1.32 & Grøwth \\
\hline 5 & 0.04 & 0.040 & 5.91 & $9.06 \times 10^{-3}$ & $7.43 \times 10^{-3}$ & 2.57 & 1.55 & Grøwth \\
\hline 6 & 0.045 & 0.045 & 5.89 & $9.81 \times 10^{-3}$ & $7.90 \times 10^{-3}$ & 2.95 & 1.78 & Grøwth \\
\hline 7 & 0.050 & 0.05 & 5.83 & $1.06 \times 10^{-2}$ & $8.34 \times 10^{-3}$ & 3.31 & 2.04 & Grøwth \\
\hline 8 & 0.055 & 0.055 & 5.82 & $1.13 \times 10^{-2}$ & $8.76 \times 10^{-3}$ & 3.72 & 2.24 & Grøwth \\
\hline , & 0.060 & 0.060 & 5.91 & $1.20 \times 10^{-2}$ & $9.15 \times 10^{-3}$ & 4.17 & 2.51 & Grøwth \\
\hline 10 & 0.065 & 0.065 & 5.88 & $1.27 \times 10^{-2}$ & $9.53 \times 10^{-3}$ & 4.57 & 2.75 & Grøwth \\
\hline 11 & 0.07 & 0.07 & 5.93 & $1.34 \times 10^{-2}$ & $9.88 \times 10^{-3}$ & 5.01 & 3.02 & Grøwth \\
\hline 12 & 0.075 & 0.075 & 5.92 & $1.41 \times 10^{-2}$ & $1.02 \times 10^{-2}$ & 5.37 & 3.31 & Grøwth \\
\hline
\end{tabular}

the monolayers that formed on the anhydrite $(10)$ and (10) surfaces. In these experiments, the lateral (frictional) force was recorded during the scanning and was used to construct the images. The frictional contrast images allowed one to infer the orientation of the outernost sulphate groups in both the newly-grown monolayers and the original anhydrite $(1 \bullet \mathbf{0})$ and $(1 \bullet)$ original surfaces. The images were recorded using silicon nitride tips (Veeco NP) with a nominal force constant of $k=0.12 \mathrm{~N} / \mathrm{m}$ and by setting the scan angle to $90^{\circ}$. The tip velocity was $61 . \mu \mathrm{m} / \mathrm{s}$ and the tip-substrate force was increased to maximise the frictional contrast.

\section{EXPERIMENTAL RESULTS}

\subsection{Dissolution of anhydrite surfaces}

Anhydrite $(\bullet 1),(\bullet 1 \bullet)$, and $(1 \bullet \bullet)$ cleavage surfaces show clear differences in dissolution behaviour when placed in deionised water (see Fig. 1). On anhydrite (1) surface, dissolution mainly occurs by the rapid retreat of the $[10]$ macrosteps (Fig. 1a). In contrast, on the $(10)$ and $(10)$ faces the main dissolution mechanism is the nucleation and growth of etch pits (Fig. 1b d). On both surfaces, two kinds of etch pits are formed: shallow and deep. Shallow etch pits nucleate randomly over the surface and are half a unit cell in depth $(\sim 3.5 \AA)$. On the $(1)$ face the shallow etch pits are rectangular, with sides parallel to the $[1 \div]$ and $[01]$ directions, and opening rates of $\sim 2 \mathrm{~nm} / \mathrm{s}$ along [ 1 ] and $\sim .2 \mathrm{~nm} / \mathrm{s}$ along $[1 \bullet$ ] (Fig. 1b). Differently, shallow etch pits on the $(1 \bullet 0)$ surfaces are elongated along the [0 1] direction and their growth is highly anisotropic; once a pit nucleates on the surface, it grows quickly in the [ 1 ] direction and slower in the opposite $[0 \overline{1}]$ direction, being the total $\langle 1\rangle$ opening rate of about $9.6 \mathrm{~nm} / \mathrm{s}$. These fast and slow directions are reversed in successive $(1 \bullet \mathbf{0})$ monolayers (Fig. 1c). In contrast, in the perpendicular direction, i.e. the $[10]$ direction, no alternate dissolution anisotropy is observed and constant opening rates of about $0.5 \mathrm{~nm} / \mathrm{s}$ have been measured. These observations agree with previous observations by Shindo et al. (1996). In addition, deep etch pits have been observed on the anhydrite $(1 \bullet)$ and $(1 \bullet \bullet)$ surfaces. These etch pits are not randomly distributed, but are located on highly defective regions of the anhydrite $(10)$ and $(10)$ surfaces, e.g. scratched areas or areas where cleavage steps with different orientations intersect. While on the (1) face deep etch pits are rectangular-shaped with edges parallel to the [०1] and [1 0] directions, their shape on the $(1 \bullet 0)$ face shape is defined by edges parallel to the [0 1] and the $\left\langle\begin{array}{lll}1 & 1\rangle \text { directions. }\end{array}\right.$

\subsection{Growth on anhydrite surfaces}

When the pure water in the fluid cell of the AFM is replaced by $\mathrm{CaSO}_{4}$ aqueous solutions with concentrations

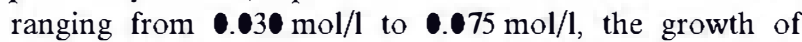
monolayers is observed on the anhydrite (1) and (1-0) surfaces. (Although the high roughness of anhydrite (-1) surfaces made it impossible to observe monolayer growth on them, such growth cannot be discarded). As in the case of dissolution, monolayer growth on different anhydrite faces shows specific characteristics. Thus, on anhydrite $(1)$ ) faces, the monolayers are $\sim 3.5 \AA$ in height and show slightly jagged growth fronts (Fig. 2). They start to grow from the edges of pre-existing cleavage steps parallel to the [ 1] direction. Neither growth from [1 10 steps nor two-dimensional nucleation were observed. High resolution AFM images of the growing anhydrite (1) monolayers show a rectangular arrangement of bright spots with translation periods of $\sim 6.5 \AA$ and $\sim 7.2 \AA$ along the [ 1 ] and $[1 \bullet]$, respectively (Fig. 3a). As can be seen in Fig. 3b such an arrangement is identical to that observed on the anhydrite $(1)$ ) original substrate. In addition, LFM images taken during growth did not show frictional contrasts between the original $(10)$ surfaces and the newly-forned monolayers.

Monolayer growth on the anhydrite $(1 \bullet \mathbf{0})$ surfaces differs from that observed on the $(1)$ ) surfaces. Fig. 4 shows a typical growth sequence. As can be observed in Fig. 4a and $b$, a first monolayer with a very jagged front $(\sim 3.5 \AA$ in height) advances over the anhydrite $(1 \bullet \mathbf{0})$ surface. This first monolayer grows until an anhydrite step edge $(\sim 7 \AA$ in height) is reached. A second monolayer, also $\sim 3.5 \AA$ in height, is then able to grow over the previous one (Fig. 4c 

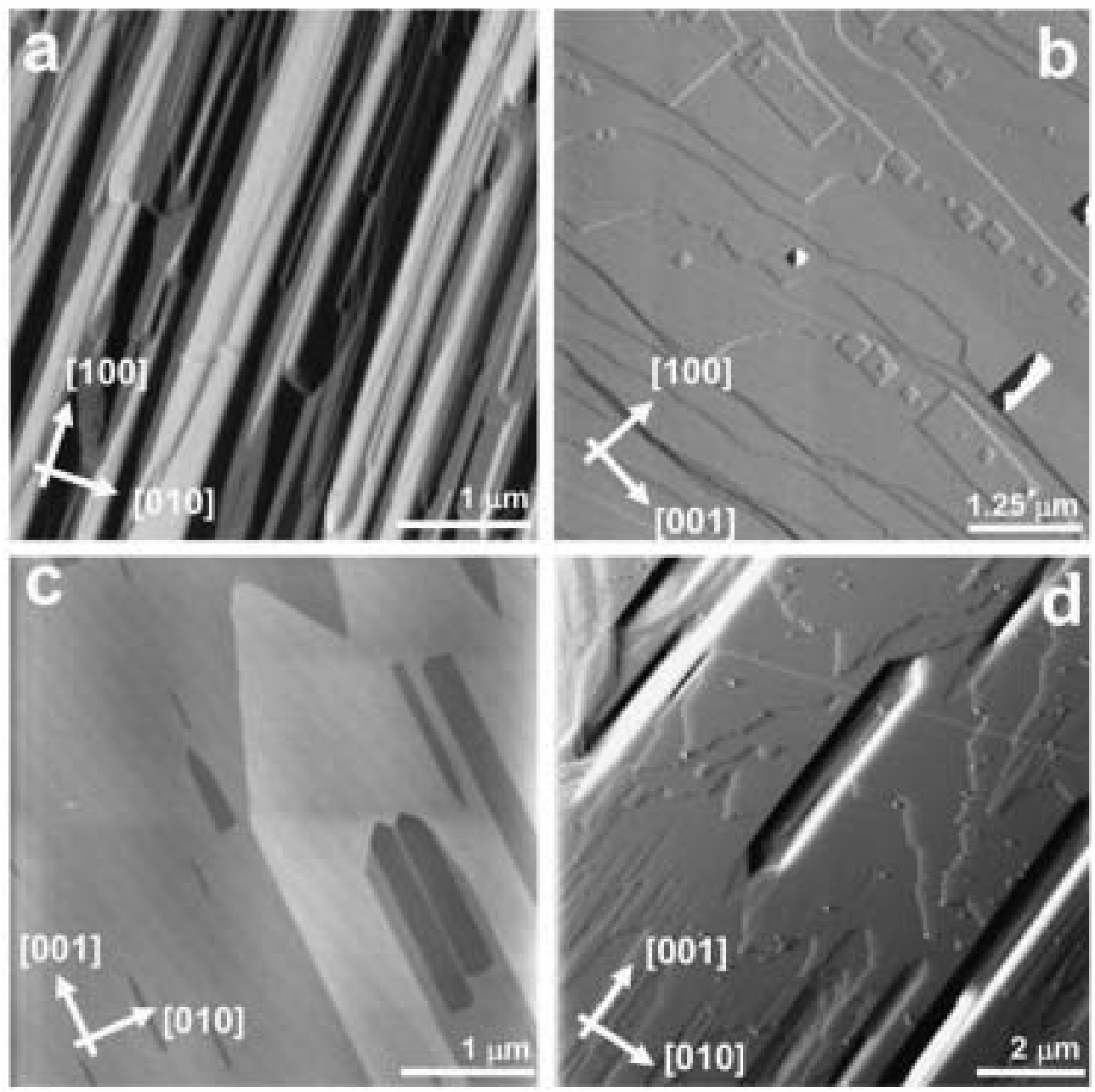

Fig. 1. Dissolution of anhydrite cleavage surfaces in deiønised water. (a) AFM defl

formation of $(10)$ terraces. (b) AFM defl

an anhydrite $(10)$ face. (c) AFM height image showing the formation of shalløw (half a unit cell in depth, $\sim 3.5 \dot{A}) \bullet n$ an anhydrite $(1 \bullet 0)$ face. (d) AFM defl

directions. The main crystallographic directions are indicated in the figures by white arrøws.

and d). When two monolayers are completed, no discontinuity with the original anhydrite one-unit cell steps $(\sim 7 \AA)$ can be observed. The growth of monolayers always starts from pre-existing cleavage steps and two-dimensional nucleation on anhydrite $(10)$ faces was never observed. High resolution AFM images of newly-grown monolayers on anhydrite $(10)$ faces show again a rectangular arrangement of bright spots with the translation periods of $-6.5 \AA$ and $\sim 7.2 \AA$ along the $\left[\begin{array}{ll}1\end{array}\right]$ and $[10]$ directions, respectively (Fig. 5a). As in the case of the (1), the rectangular lattices on the original substrate and on the newly-grown (1) terraces are identical (Fig 5b).

Under optimised conditions (i.e. the [ 1] direction parallel to the scan direction, high scan velocity, and high tip-substrate force), LFM images of anhydrite $(10)$ surfaces, on which growth had been previously observed, show a clear contrast between the newly-formed monolayers and the original anhydrite substrate (Fig. 6). This frictional contrast can be attributed to differences in the orientation of the sulphate groups in successive monolayers, and will be discussed in Section 42.
Fig. 7 shows plots of the monolayer advancement rate on the anhydrite $(10)$ and $(10)$ faces versus the concentration of $\mathrm{CaSO}_{4}$ in the aqueous solution. While on the (1) face growth rates were measured along the [1 10$]$ direction, on the $(1 \bullet)$ face measurements were done along the [1] direction, i.e. perpendicular to the step edge directions. In both cases, growth rates increase rapidly with increasing $\mathrm{CaSO}_{4}$ concentration.

\section{DISCUSSION}

\subsection{Kinetics of dissolution and growth on anhydrite surfaces}

AFM observations of anhydrite $(1 \bullet)$, and $(1 \bullet \bullet)$ faces show a strong anisotropy of the nanostep retreat and growth rates. This evidences a common and face-specific crystallographic control of both the dissolution and growth processes on a nanoscale. Such a control can be qualitatively explained in terms of the orientation, structure, and stability of the Periodic Bond Chains (PBCs), that define 

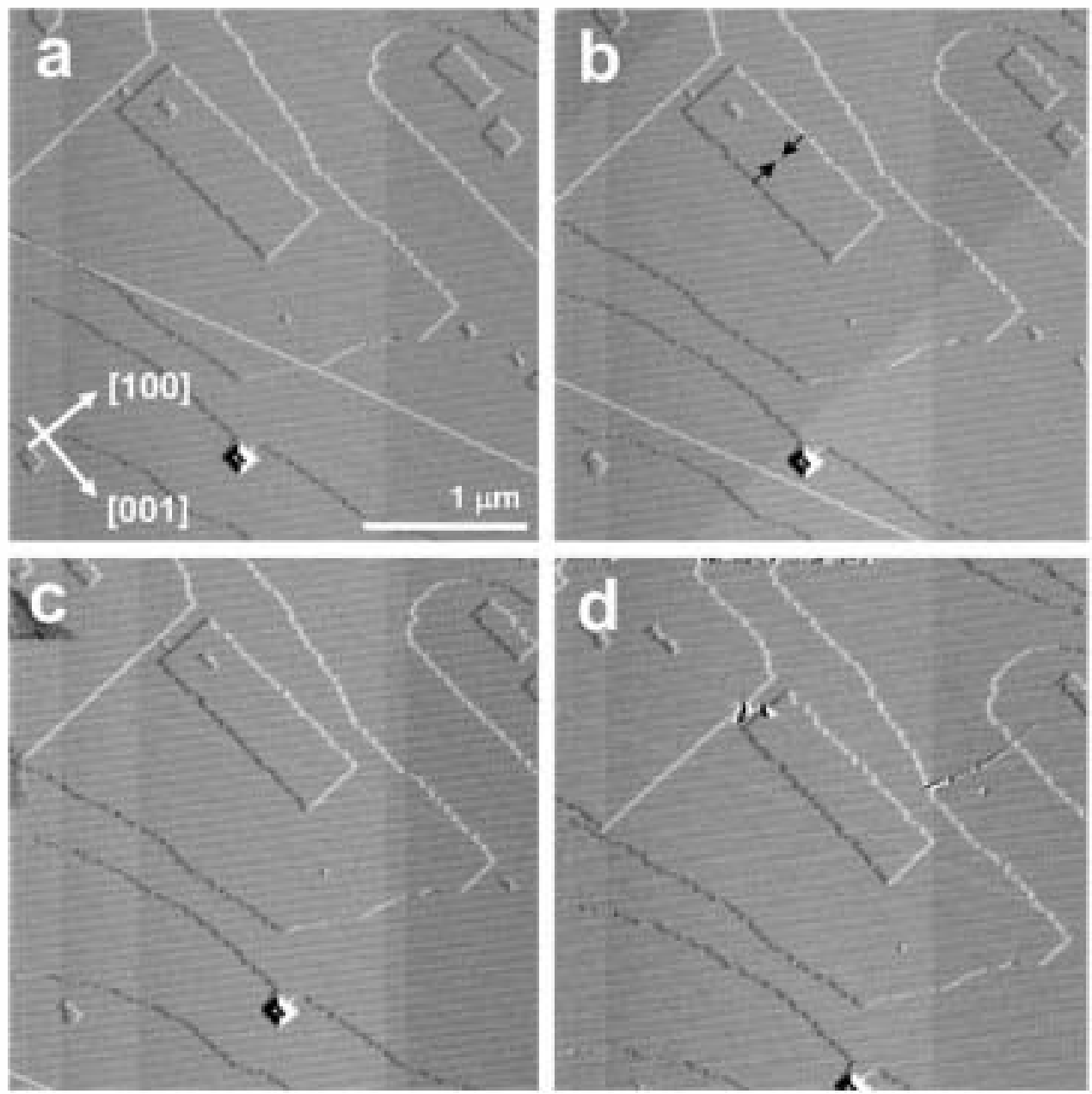

Fis. 2. (a-d) Sequence of in situ AFM defl.

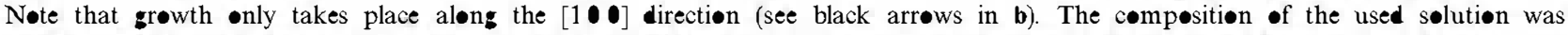

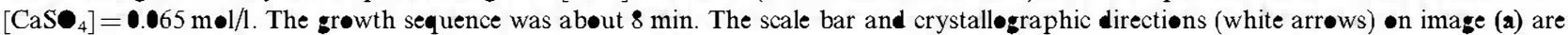
valid for all the images.
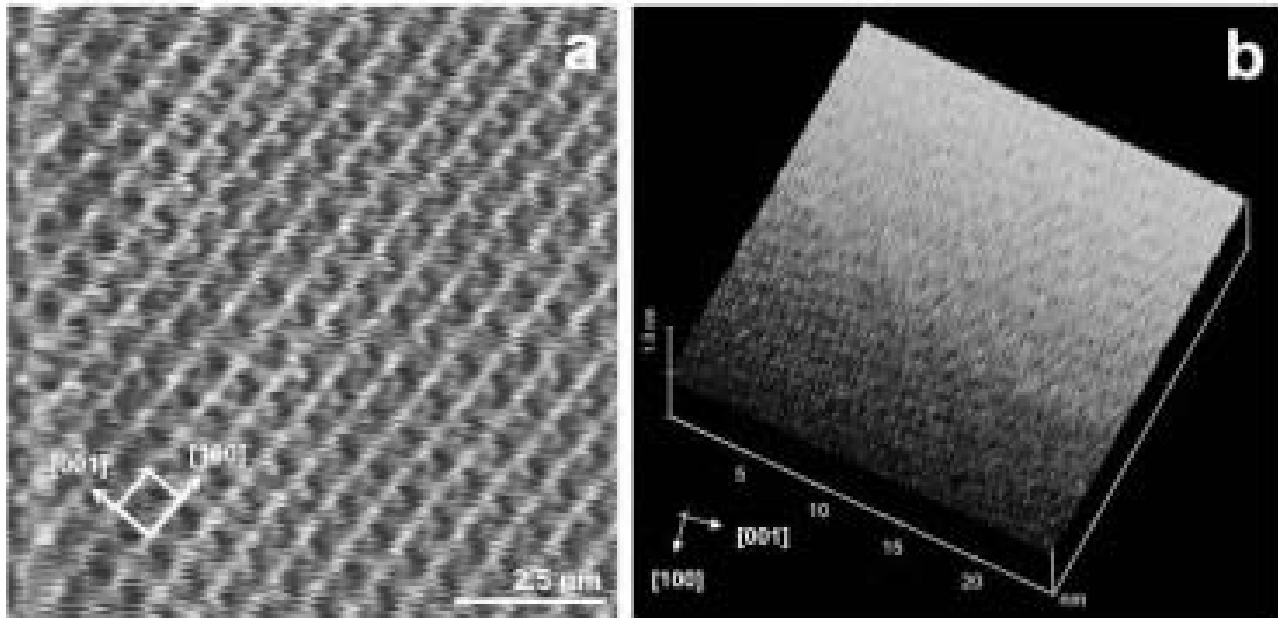

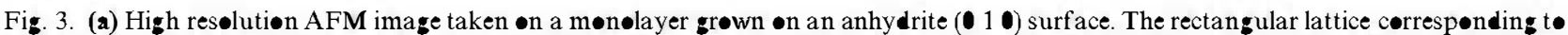

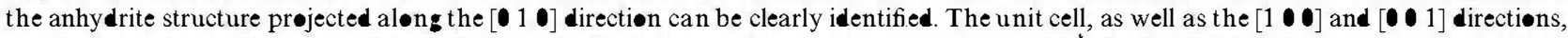

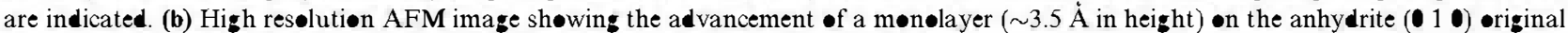
substrate. Note the perfect match between the substrate and •vergrøth structures. 

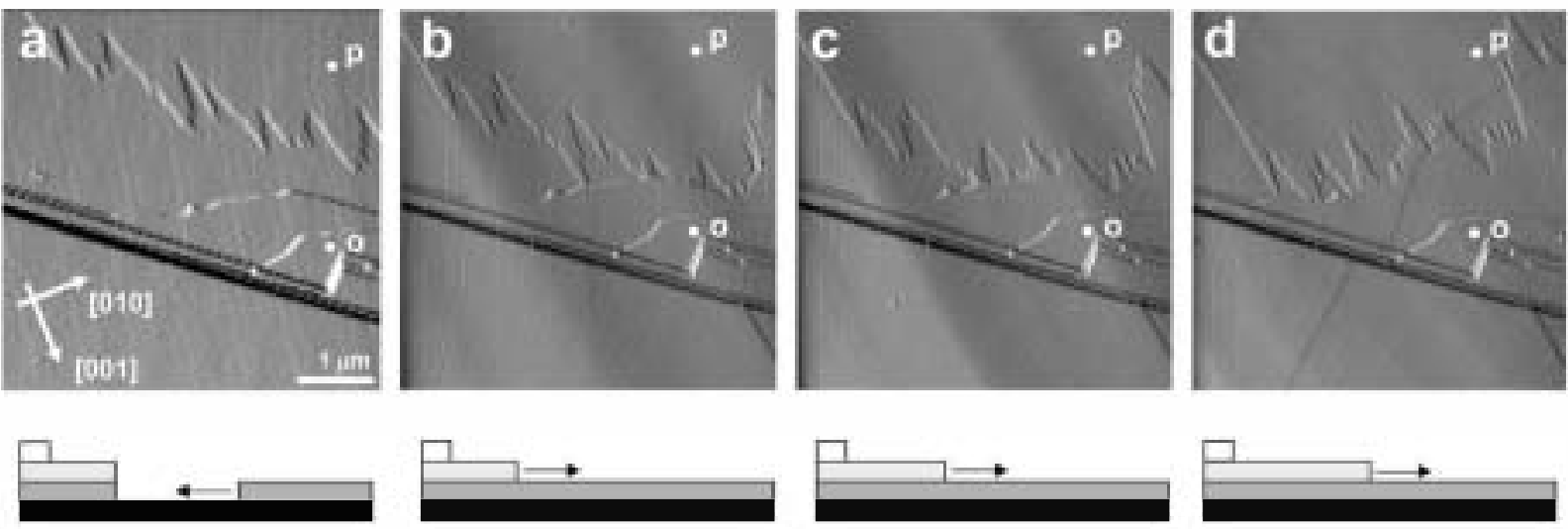

o
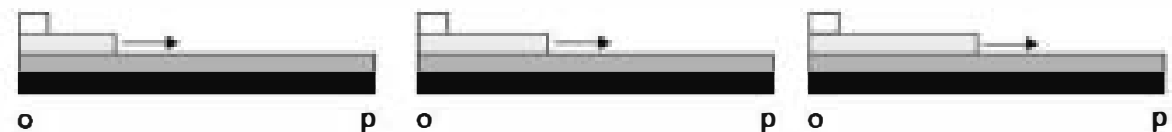

Fig. 4. (a-d) Sequence of AFM defl

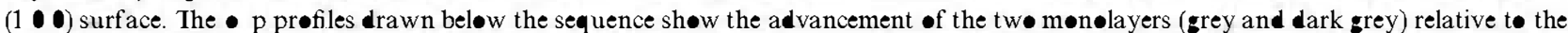

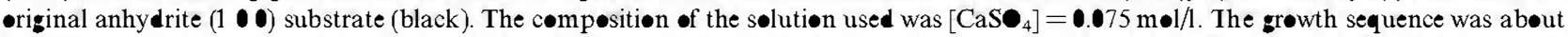
$6.2 \mathrm{~min}$. See explanation in the text. The scale bar and crystallographic directions (white arrøws) $\bullet$ n image (a) are valid for all the images.
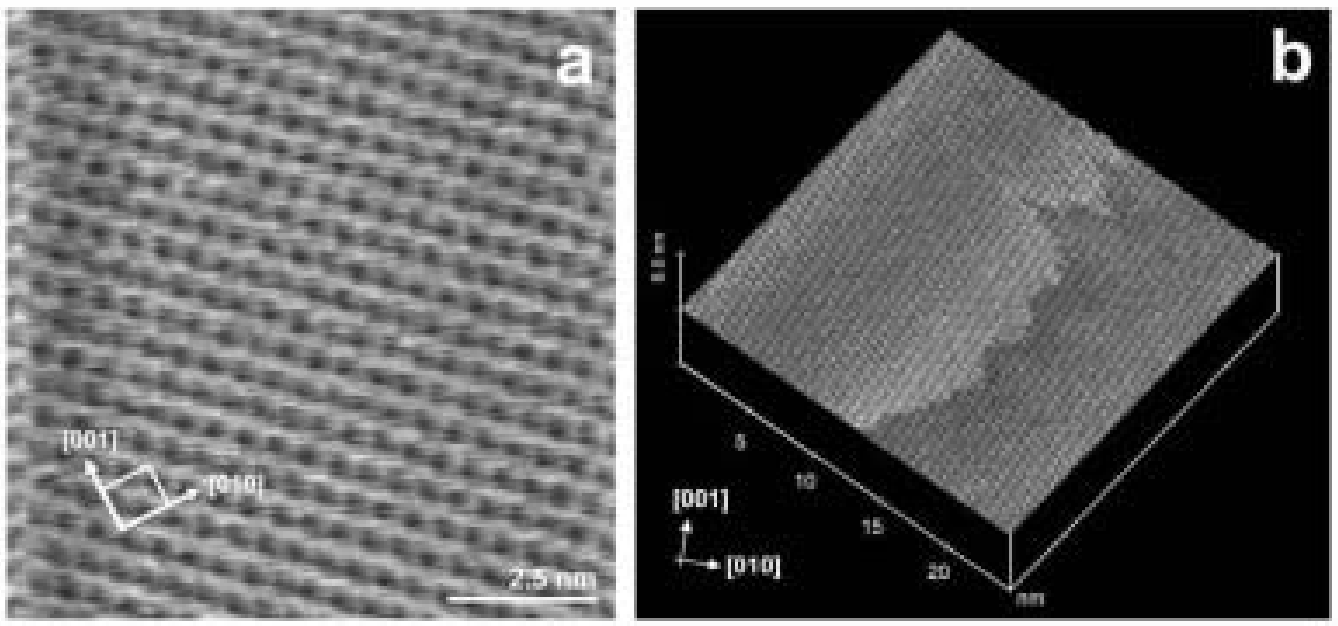

Fig. 5. (a) High reselution AFM image taken on a flat

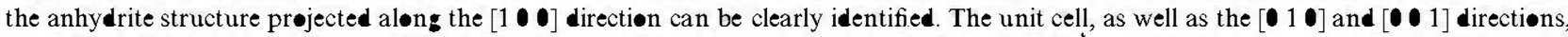

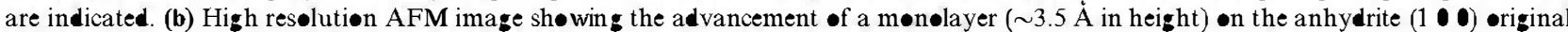
substrate. Note the perfect match between the substrate and overgrowth structures.

the step edges on anhydrite monolayers (Shindo and Nozoye, 1992; Hartman, 1988 and references therein).

Shallow rectangular-shaped etch pits on anhydrite (1 ) face are $\sim 3.5 \AA$ in depth and bounded by steps parallel to the $[\bullet 1]$ and $\left[\begin{array}{ll}1 & \bullet\end{array}\right]$ directions (Fig. 1b). The depth and the shape of these etch pits are consistent with a structural anhydrite $(20)$ slice with thickness $\boldsymbol{d}_{\mathbf{0} 2}=3.5 \AA$, and the existence and stability of PBCs along the step edges that define such etch pits (see Fig. 8a). Although the stability of these step edges is of the same level, they show some significant differences (Shindo et al., 1996). While there are two possible configurations for the $[1-0]$ step edges (stable and unstable) only one stable configuration for the [ 1 ] step edge can be defined (the unstability of a step edge configuration is due to a large local polarity that favours the solvation of constituent ions). According to Shindo et al., 1996 , solvation of sulphate groups is stronger along the unstable $\left[\begin{array}{lll}1 & 0\end{array}\right]$ step edges and they leave easier the step. As a consequence, during dissolution in pure water, [1 - e] steps are slightly more reactive and retreat at higher rates than the structurally more stable [ 1] steps. This is consistent with the rectangular shape of the etch pits on (1 ) face. However, as Shindo et al. (1996) also reported, the relative retreating velocities of the [ 11$]$ and [ $\left[\begin{array}{ll}1 & 0\end{array}\right]$ directions are reversed for high concentrations of $\mathrm{CaSO}_{4}$ due to the charge neutralisation (stabilisation) of the step edges by the ions in the solution. At $\mathrm{CaSO}_{4}$ concentrations close to saturation with respect to anhydrite, $\left[\begin{array}{lll}1 & 0\end{array}\right]$ steps become static, whereas [ 1 1] steps still dissolve at measurable rates. This change in reactivity persists, when supersaturated solutions with respect to anhydrite are used, i.e. the [1 10$]$ steps remain immobile and [01] steps grow with increasing speed as the $\mathrm{CaSO}_{4}$ concentration in the aqueous solution increases (see Fig. 2 and Fig. 7a). 


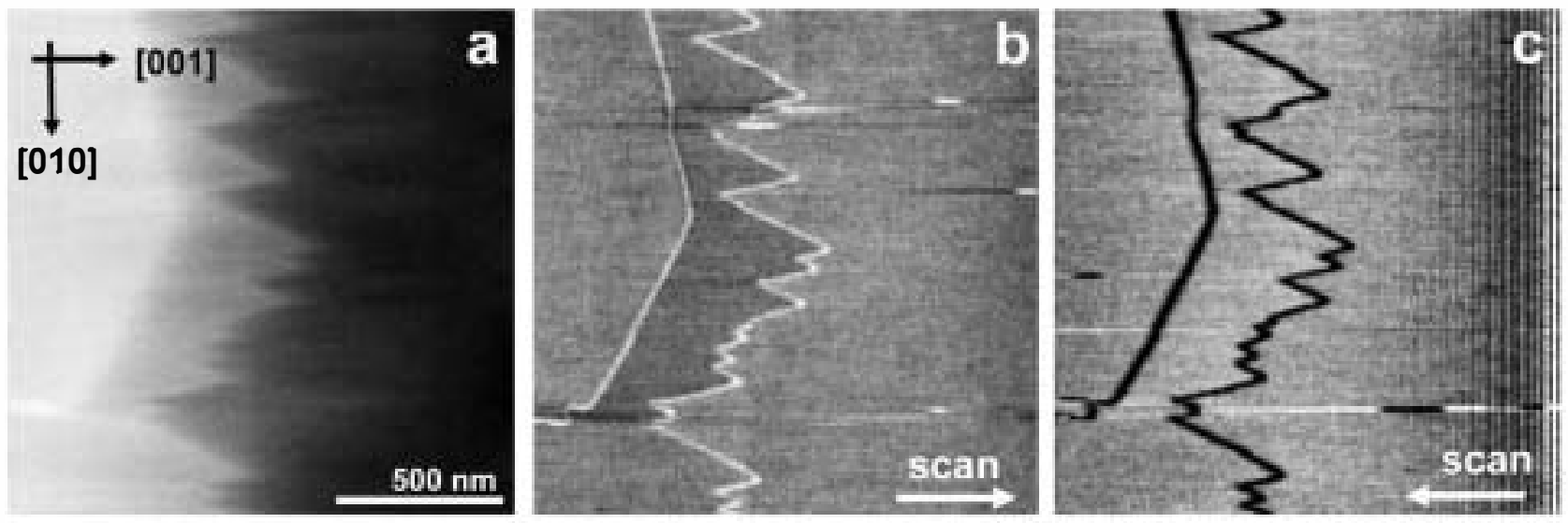

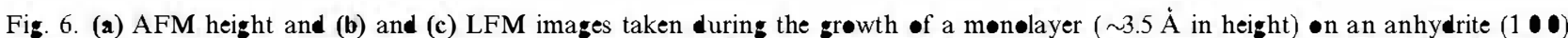

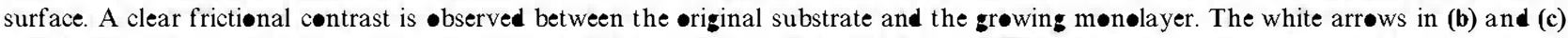
indicate the fast scan directions. The compøsition of the sølution used was $\left[\mathrm{CaS}_{4}\right]=\mathbf{0 . 0 3} \mathrm{m} \bullet 1 / \mathrm{l}$.
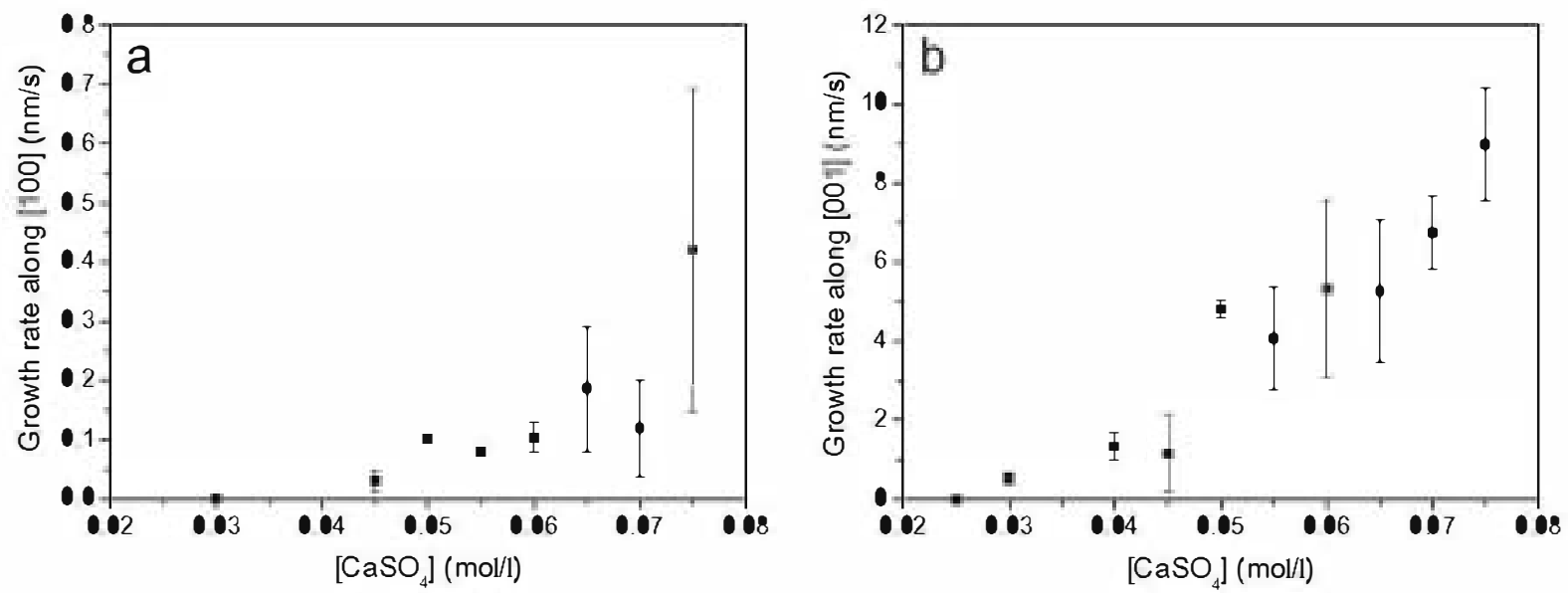

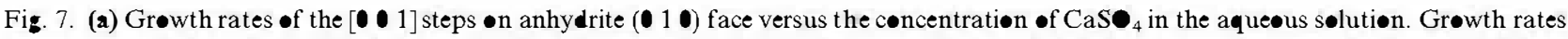

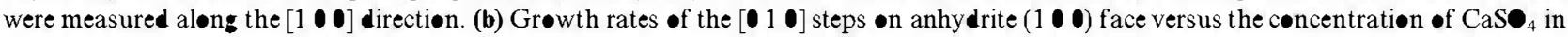
the aqueous solution. Growth rates were measured along the $\left[\begin{array}{lll}0 & 1\end{array}\right]$ direction.

A similar change in the direction of the step motion from dissolution to growth also occurs on the anhydrite (1 0) face. However, in this case the crystallographic control is more complex. In pure water, shallow etch pits on anhydrite $(1 \bullet$ ) face are also $\sim 3.5 \AA$ in depth, which is consistent with a structural anhydrite $(2 \bullet \mathbf{0})$ slice with thickness $\boldsymbol{d}_{200}=3.5 \AA$. As it occurred on the $(1)$ face, the etch pits are elongated along the $\left[\begin{array}{ll}0 & 1\end{array}\right]$ direction, i.e. parallel to PBCs with only an electrically stable configuration (Fig. 8b). In contrast, the two terminations of the (1 0) etch pits are different and their retreat is highly anisotropic. This is due to the different configuration of the [1 step edges pointing toward the inner part of the etch pits (see Fig. 8b). While [1 10 steps edges defined by the $\mathrm{SO}_{4}^{2}$ apex are unstable and retreat at a high velocity, the [ 10 steps whose edges are defined by the $\mathrm{SO}_{4}^{2}$ basis are more stable and retreat more slowly (and therefore a straight [ 10 ] step edge is stabilised). (Shindo et al., 1996). Since each $d_{200}$ slice is related to the slice underneath by a $2_{1}$ screw axis, the orientation of sulphate groups along the [ 10 PBCs in two successive $d_{200}$ slices is reversed. As a result, the $[01]$ directions with rapid and slow retreat velocities alternate during the layer-by-layer dissolution. The alternation of rapid and slow monolayers leads to the stabilisation of step edges parallel to the $\left.\begin{array}{lll}1 & 1 & 1\end{array}\right\rangle$ directions, which can be only observed in etch pits deeper that two monolayers. When anhydrite $(1 \bullet \bullet)$ surfaces are placed in $\mathrm{CaSO}_{4}$ solutions with increasing supersaturation with respect to anhydrite, the growth of the unstable and more reactive [1 ] step edges is observed (Fig. 4 and Fig. 7b). In addition, as in the case of dissolution, the 21 screw axis that relates two structural $\boldsymbol{d}_{20}$ slices, leads to the reversal of fast and slow growth directions in successive monolayers. Conversely, stable [1] step edges remain immobile in supersaturated solutions with respect to anhydrite.

The crystallographic control of the retreat and advancement of monosteps discussed above indicates that dissolution and growth on anhydrite surfaces occurs by a common mechanism in which the direction of migration of crystal building units is simply reversed. This idea can 

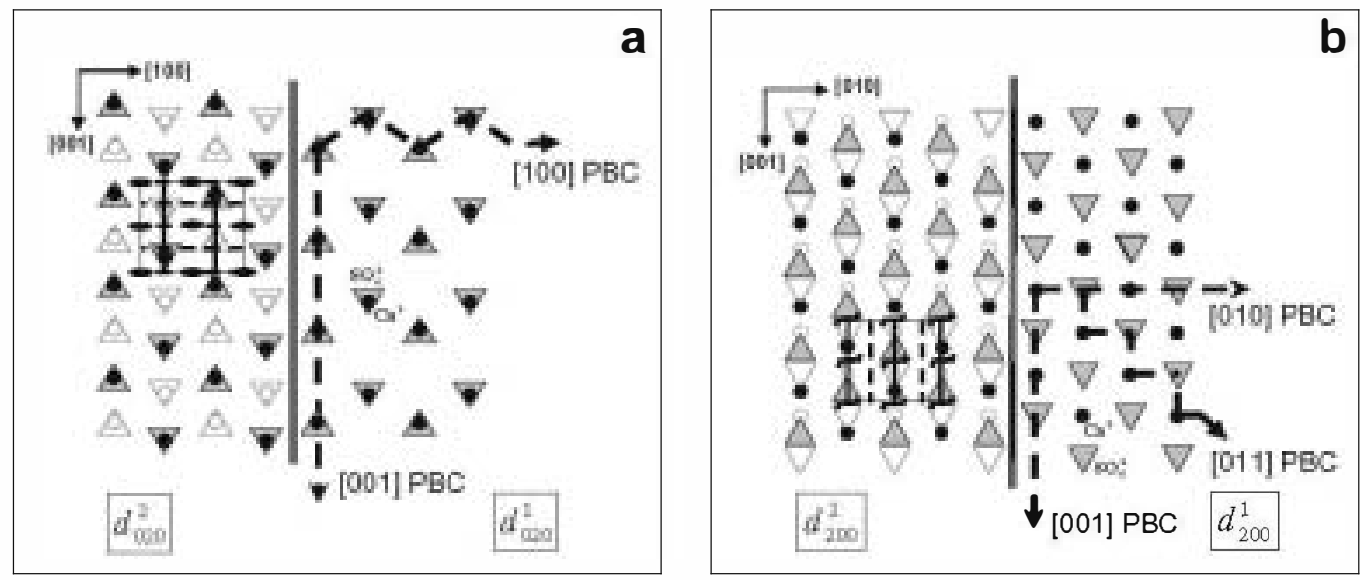

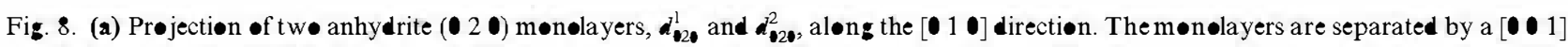

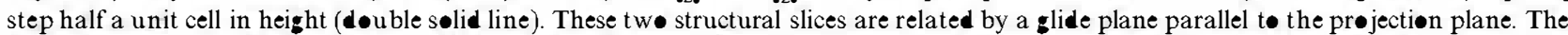

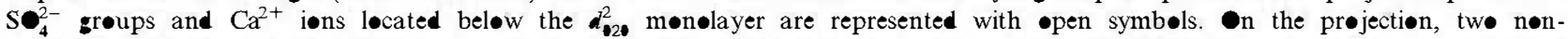

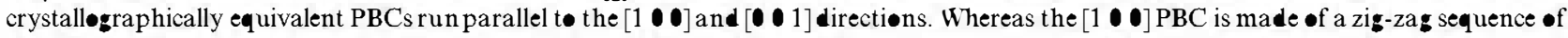

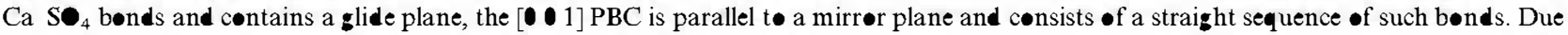

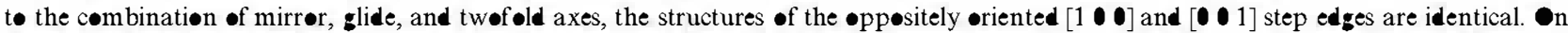

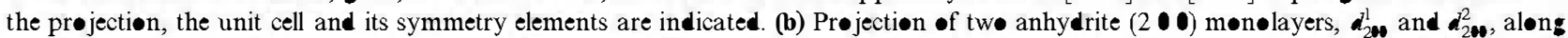

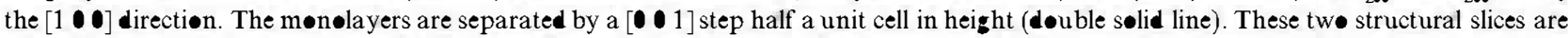

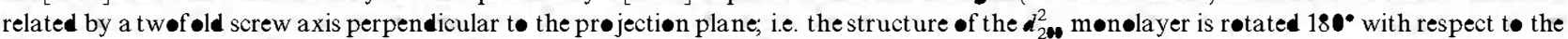

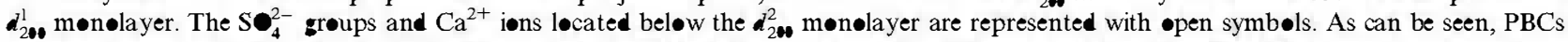

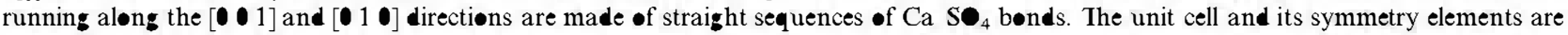
indicated.

be further discussed by comparing the kinetics of dissolution and growth of monosteps. Figs. $9 \mathrm{a}$ and $\mathrm{b}$ show the dissolution and growth rates of steps on the $(1 \bullet)$ and $(10)$ anhydrite faces as a function of the undersaturation/supersaturation with respect to anhydrite. According to the Zhang and Nancollas model (Zhang and Nancollas, 1990, 1998), dissolution and growth rates of a given monostep as a function of the undersaturation/supersaturation can be described by two complementary equations. However, the Zhang and Nancollas model is based on a number of idealisations and assumptions, mainly regarding the geometry, density, and dynamics of kink sites, that can limit its applicability to relatively complex crystal faces like anhydrite surfaces (see $\mathrm{Hu}$ et al., $\mathbf{2 0 0 5}$ for a discussion on the validity of the Zhang and Nancollas model, and Chernov, 2001; Chernov et al., 2005 and Cuppen et al., 2004 for new insights on kink densities and step flow models). Therefore, the following use of the Zhang and Nancollas model should be considered only as a simple way of comparing and discussing the dissolution and growth kinetics of monolayers on anhydrite $(10)$ and $(10)$ faces. The aim is not to accurately predict step motion on such anhydrite surfaces, but rather to show that dissolution and growth on anhydrite surfaces are controlled by the attachment/detachment of the same kind of building units. According to Zhang and Nancollas (1990) and Zhang and Nancollas (1998), the rates of both dissolving and growing steps can be described by using the following two equations:

$$
\begin{aligned}
& v_{d}^{\mathrm{uvw}}=C_{\mathbf{u}}^{\mathrm{uvw}} \frac{\left(S_{\mathrm{anh}}-1\right)}{\sqrt{2-S_{\text {anh }}}} \quad S_{\text {anh }}<1 \\
& v^{\mathrm{uvw}}=C^{\mathrm{uvw}}\left(S_{\mathrm{anh}}-1\right) \sqrt{S_{\text {anh }}} \quad S_{\text {anh }}>1
\end{aligned}
$$

where $v_{d}^{u v w}$ and $v_{\varepsilon}^{u v w}$ are the dissolution and growth velocities for steps parallel to a given [uvw] crystallographic direction, $C_{d}^{\text {unw }}$ and $C_{z}^{\text {uvw }}$ are the dissolution and growth rate constants, respectively, and $S_{\text {anh }}=\sqrt{\beta_{\text {anh }}}$ is the supersaturation/undersaturation of the aqueous solution with respect to anhydrite. The growth and dissolution curves shown in Fig. $9 \mathrm{a}$ and $\mathrm{b}$ were obtained by fitting Eqs. (3) and (4) to the experimental data, while taking the rate constants as fit parameters. In the case of dissolution, the fitting process was conducted while excluding the data for $S_{\text {anh }}$ close to zero. This is because a high kink density along the steps is expected at very low undersaturations and, therefore, the applicability of Eq. (3) is questionable (Zhang and Nancollas, 1990; Hu et al., 2005). As can be seen, Eqs. (3) and (4) are able to describe both sets of experimental data quite well, indicating that no critical supersaturation of anhydrite is required to initiate the dissolution or growth of the steps on the $(1 \bullet)$ and $(10)$ faces. Hence, the switch from dissolution to growth occurs at $S_{\mathrm{anh}}=1$. However, dissolution and growth kinetics are not completely symmetrical with respect to the $S_{\text {anh }}=1$ line; i.e. the dissolution and growth rates of a given monostep differ at equal and opposite distances from anhydrite equilibrium solubility. Kinetic Monte Carlo simulations by Cheng (1993) showed that crystal dissolution and growth rate constants for monosteps are similar and do not differ by more than $\sim 50 \%$. According to $\mathrm{Hu}$ et al. (2005), small differences in the rate constants and kinetic asymmetry are related and are consistent with the model of Zhang and Nancollas. This slight kinetic asymmetry is reflected in the calculated rate constants: $C_{d}^{[010]}=3.11 \pm .42$ and $C^{[010]}=7.14 \pm .42$ for the [1 steps propagating on anhydrite $(1 \bullet \mathbf{0})$ faces, and $C_{d}^{[001]}=.2 \pm \pm 02$ and $C^{[001]}=.25 \pm \mathbf{0 . 0 4}$ for the 

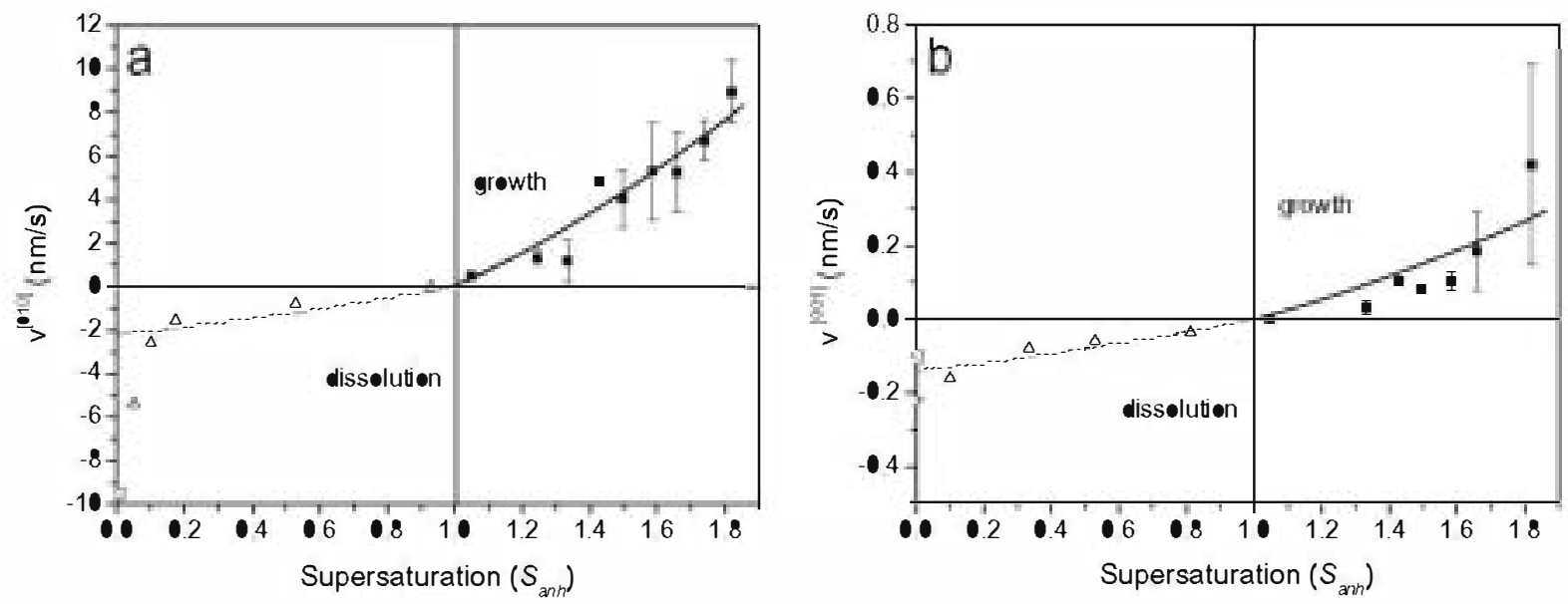

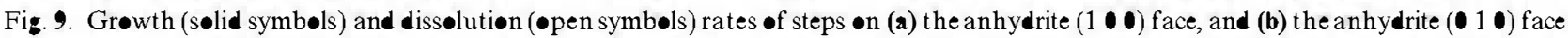

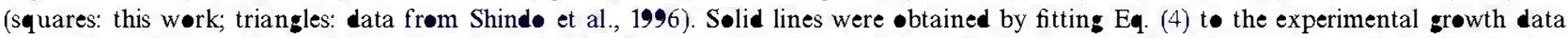

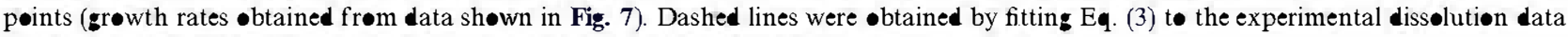

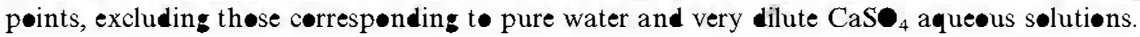

[0 1] steps propagating on anhydrite $(10)$ faces. In both cases, the calculated growth rates constants are higher than the dissolution rate constants. This result may be related to the dependence of kink-site density on solute concentrations, as was predicted by the Zhang and Nancollas model. Furthermore, a non-linear dependency of the step rates on supersaturation/undersaturation would indicate a onedimensional nucleation mechanism of kink generation along the anhydrite steps.

Although the advancement and retreat of the most reactive anhydrite steps reverse at the anhydrite saturation point, two main differences between dissolution and growth on anhydrite surfaces must be pointed out: (i) while step generation mainly occurs during dissolution by two-dimensional nucleation of etch pits, two-dimensional nucleation of growth islands was never observed; (ii) step growth only occurs from certain pre-existing step edges whereas in pure water all the steps edges are reactive. These differences between dissolution and growth indicate high activation energies for both two-dimensional nucleation of islands on the anhydrite surfaces and advancement of steps (i.e. for onedimensional nucleation along step edges). As it was recently shown, high activation energies for step generation and propagation can play a critical role in determining the kinetics of multilayer growth on mineral surfaces at room temperature (Saldi et al., 2009). Therefore, in order to determine the activation energies and obtain anhydrite face rates, further investigations on the anhydrite growth kinetics as a function of temperature are required.

\subsection{The structure of the growth monolayers on anhydrite surfaces}

The nanoscale observations reported in this work show that monolayer growth only occurs on anhydrite (1 0) and $(10)$ faces from $\mathrm{CaSO}_{4}$ solutions supersaturated with respect to anhydrite. Moreover, step kinetics discussed in the previous section indicates that dissolution and growth on anhydrite surfaces essentially take place by the same mechanism. However, gypsum and not anhydrite is the stable calcium sulphate phase at room temperature and all the solutions used in this work are supersaturated with respect to gypsum (see Table 1). Despite this, the information provided by both high resolution AFM images and LFM images clearly confirm that the newly-formed monolayers are of anhydrite. This new information discard the possible formation of first epitaxial monolayers with a gypsum-like structure on anhydrite surfaces, as it was previously interpreted on the basis of preliminary AFM observations and computer simulations (Pina et al., 2000). High resolution AFM images of the first monolayer grown on anhydrite (10) face allow one to identify a rectangular lattice defined by bright spots (see Fig. 3a). Measured translational vectors along the $\left[\begin{array}{lll}1 & 0\end{array}\right]$ and $\left[\begin{array}{ll}1 & 1\end{array}\right]$ directions are consistent with the dimensions of anhydrite unit cell, i.e. $\boldsymbol{a}_{\mathbf{0}}=\mathbf{7 . 0 0 6} \AA$, $c_{0}=6245 \AA$. In addition, the identical dimensions and orientation of the rectangular lattices of the first monolayer and the original $(10)$ substrate further demonstrate that the growing phase is anhydrite. Similarly, a rectangular lattice of bright spots can be recognised on the high resolution AFM images of the first monolayer formed on the anhydrite $(1 \bullet 0)$ substrate (see Fig. 5a). Translational periods along the [1 101 and [1rections are consistent with the anhydrite unit cell, $\left(b_{\bullet}=6.998 \AA, c_{0}=6.245 \AA\right)$ and the identical overgrowth and substrate lattices again allow one to conclude that the newly-grown monolayer is anhydrite.

The bright spots that define the rectangular lattices in the high resolution AFM images shown in Figs. 3 and 5 correspond to outermost oxygen atoms belonging to the sulphate groups in the anhydrite monolayers (Shindo et al., 1992; Shindo and Nozoye, 1992). Nevertheless, these high resolution AFM images do not provide information about the relative orientation of sulphate groups in successive anhydrite monolayers. Such an information is, however, important to completely characterise the growth of 
the first monolayers on anhydrite substrates and it can be obtained from LFM images.

According to Shindo et al. (1999a,b), differences in contrast in LFM images of anhydrite $(10)$ faces are due to the alternating tilt of the outermost $\mathrm{SO}_{4}^{2}$ tetrahedra in successive terraces. When the outermost $\mathrm{S}-\mathrm{bonds}$ in the outermost $\mathrm{SO}_{4}^{2}$ tetrahedra in the terrace are tilted toward the scan direction, the friction between the AFM tip and the anhydrite $(10)$ surface is low. Conversely, when the outermost $\mathrm{SO}_{4}^{2}$ tetrahedra are tilted away from the scan direction, the friction between the AFM tip and the surface is higher. Since successive anhydrite $(1 \bullet \mathbf{0})$ monolayers (half a unit cell in height, $\sim 3.5 \AA$ ) are related by a $2_{1}$ screw axis, the orientation of $\mathrm{SO}_{4}^{2}$ tetrahedra on anhydrite $(1 \bullet \mathbf{0})$ terraces can be inferred from the differences in friction. LFM images taken during the growth on anhydrite $(10)$ faces show a significant contrast between the newly-grown monolayers and the original cleavage surface. In Figs. $6 \mathrm{~b}$ and $\mathrm{c}$, the monolayer $(\sim 3.5 \AA$ in height $)$ growing from a step edge one unit cell in height $(\sim 7 \AA$ ) shows a dark contrast (lower tip-surface friction) and a bright contrast (higher friction) when the scan direction is reversed. Therefore, it can be concluded that the outermost $\mathrm{SO}_{4}^{2}$ tetrahedra in growing monolayers are oriented opposite to those in the terraces underneath. This is consistent with the growth of elementary $\boldsymbol{d}_{20}$ growth layers related to the original $(1 \bullet \mathbf{0})$ anhydrite surface by a 21 screw axis (see Fig $8 b$ ).

On the anhydrite $(10)$ face the situation is different. Although, as in the case of the anhydrite $(10)$ face, successive $(10)$ monolayers are also half a unit cell in height, all the monolayers display an identical distribution of $\mathrm{SO}_{4}^{2}$ tetrahedra tilted in opposite directions (see Fig. 8a). As a result, the AFM tip always encounters the same mechanical resistance during the scan and, therefore, successive monolayers cannot give differences in friction contrast. LFM images recorded during the advancement of monolayers on anhydrite (1) faces do not show any contrast, indicating an identical distribution and orientation of outermost $\mathrm{SO}_{4}^{2}$ tetrahedra in successive (10) growth monolayers.

\section{CONCLUDING REMARKS}

In situ AFM observations presented in this paper reveal a high molecular-scale reactivity of anhydrite $(10)$ and (1 0) faces in both pure water and supersaturated solutions with respect to anhydrite. Dissolution and growth kinetics are surface-specific, highly anisotropic and strongly controlled by the structure and symmetry of anhydrite (1) and $(1-0)$ faces. Furthernore, the analysis of the monostep motion around the anhydrite saturation state shows that the dissolution and growth mechanisms on anhydrite $(1 \bullet \mathbf{0})$ and $(1 \bullet)$ surfaces are essentially the same, with the direction of migration of crystal building units being reversed at the anhydrite saturation point. However, there are significant differences concerning step generation and propagation that make the kinetics of dissolution and growth of anhydrite surfaces very different.

Finally, it is important to note that the growth of anhydrite monolayers at room temperature is metastable and it can be interpreted as a mechanism of momentarily reducing the free energy of the system following a kinetically favoured path. In this respect, the formation of monolayers on anhydrite surfaces might be considered as a precursor reaction which can strongly modify the kinetics of gypsification of anhydrite crystals in both laboratory and natural environments.

\section{ACKNOWIEDGMENTS}

This work was supported by the Spanish Ministry of Education and Science (Pr•ject N•. CGL2007-65523-C02-01) and the UCMComunidad de Madrid (Grant N•. 910148-Superficies Minerales).

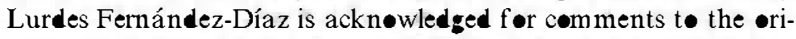

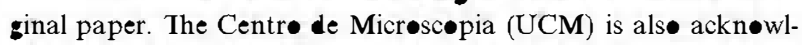
edged for kindly providing access to the AFM. This paper benefited from insightful comments by Eric $\mathrm{H}$. Oelkers and three anonymous reviewers.

\section{REFERENCES}

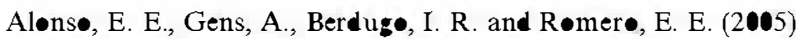
Expansive behaviour of a sulphated clay in a railway tunnel. In Proceedings of 16 th International Conference on Soils. Mechanics and Geotechnical Engineering. Millpress, Røtterdam 3, pp. 15831586.

Ball M. C. and Norwood L. S. (1969) Studies in the system calcium sulphate water. Part I. Kinetics of dehydration of calcium sulphate dehydrate. J. Chem. Soc. A, 16331637.

Bath A. H., Darling W. G., George I. A. and Milodowski A. E. $(1987){ }^{18} / /^{16}$ and ${ }^{2} \mathrm{H} /{ }^{1} \mathrm{H}$ changes during progressive hydration of Zechstein anhydrite formation. Geochim. Cosmochim. Act 51, 8113-8118.

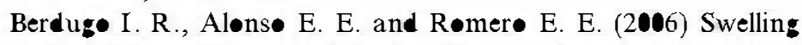
mechanisms in sulphate-bearing røcks. In Proc. Eurorock 2006 (eds. Van Cotthen, Charlier, Thimus and Tshibangu). Taylor \& Francis Grøup, Lønden, pp. 451-454.

Berduge, I. R. (2007) Swelling Mechanisms in Sulphate Bearing Rocks. PhD. Thesis, UPC.

Bøsbach D. and Rammensee W. (1994) In situ investigation of grøwth and dissolution on the $(10)$ surface of gypsum by scanning force microscopy. Geochim. Cosmochim. Act 58, 843849.

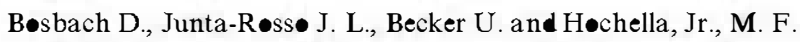
(1996) Gypsum growth in the presence of back grøund electrlytes studied by scanning førce micrøscøpy. Geochim. Cosmochim. Act 60, 3295-3304.

Bløunt C. W. and Dicksøn F. W. (1969) Sølubility of anhydrite $\left(\mathrm{CaSO}_{4}\right)$ in $\mathrm{NaCl} \mathrm{H} \mathrm{H}_{2}$ frøm 100 to $450^{\circ} \mathrm{C}$ and 1 to 1000 bars. Geochim. Cosmochim. Act 33, 227-245.

Bundy W. M. (1956) Petrølogy of zypsum-anhydrite deposits in søuthwestern Indiana. J. Sed. Petr. 26, 240-252.

Butler G. P. (1969) Mødern evapørite depøsition and geochemistry of coexisting brines, the sabkhas, Trucial Cøast, Arabian Gulf. J. Sediment. Petrol. 39, 70-89.

Cheng V. K. W. (1993) Kinetic asymmetry between crystal grøth and dissolution: Step movement at løw temperatures. J. Chem. Soc. Faraday Trans. 89, 3579-3584.

Chern॰v A. A. (2001) Crystal grøwth science between the centuries. J. Mater. Sci. Mater. Electron 12, 437-449.

Chernøv A. A., Rashkøvich L. N. and Vekiløv P. G. (2005) Steps in sølution grøwth: dynamics of kinks, bunching and turbulence. J. Cryst. Growth 275, 1-18.

Cøle W. F. and Lancucki C. J. (1974) A refinement of the crystal structure of sypsum CaS⿰ $\mathbf{9}_{4} \cdot 2 \mathrm{H}_{2}$. Acta Cryst. B 30, 921-929. 
Cønley R. F. and Bundy W. M. (1959) Mechanism $\bullet$ gypsification. Geochim. Cosmochim. Act 15, 57-72.

Cuppen H. M., Meekes H., van Enckevort and Vlieg E. (2004)

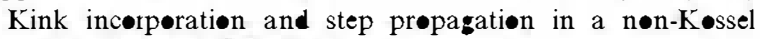
model. Surf. Sci. 571, 41-62.

D’Ans, J. (1968) Der Überganspunkt Gips-Anhydrit. Kali Steinsaltz 5, 109111 (M.A. 20-2083).

Finøt E., Lesniewska E., Mutin J.- C. and Gøudønnet J.- P. (1997) Reactivity of sysum faces according to the relative humidity by scanning force micrescepy. Surf. Sci. 384, 201-217.

Freyer D. and Voigt W. (2003) Crystallization and Phase Stability - $\mathrm{CaS}_{4}$ and $\mathrm{CaSO}_{4}{ }^{-}$Based Salts. Monatshefte für Chemie 134, 693-719.

García-Ruiz J. M., Villasus• R., Ayøra C., Canals A. and Otáløra F. (2007) Førmation of natural sypsum megacrystals in Naica, Mexic•. Geology 35, 327-330.

Gøldmann M. (1952) Def ^rmatiøn, metamerphism and mineralisation in sypsum-anhydrite cap røck of sulphur salt døme, Løusiana. Geol. Soc. Am. Mem. 50, 169.

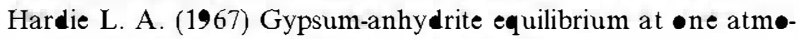
sphere pressure. Am. Mineral. 52, 171-200.

Hartman P. (1988) Morphøløgy of Crystals. In Part A, Modern $P B C$ theory (ed. I. Sunagawa). Terra Sci. Pub. C•

Hølland H. D. (2004) The geøløgical History of Seawater pp.583 625. In The ceans and Marine Geochemistry, v•l. 6 (ed. H. Elderfield) (eds. H. D. Hølland and K. K. Turekian). ElsevierPergamøn, oxf rd, pp. 2-3.

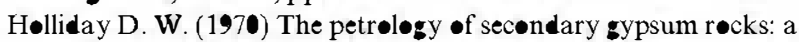
review. J. Sediment. Petrol. 40, 734-744.

Hu X., Grossie D. A. and Higgins S. R. (2005) Growth and dissolution kinetics at the dolømite water interface. An in situ scanning prøbe micrøscøpy study. Am. Mineral. 90, 963-968.

Jordan G. and Astilleres J. M. (2006) In situ HAFM study of the thermal dehydration on sypsum $(10)$ surfaces. Am. Mineral. 91, 619-627.

Kirfel A. and Will G. (1980) Charge-density in anhydrite, CaS ${ }_{4}$, from X-ray and neutron-diffraction measurements. Act Crystallogr. B 36, 2881-2890.

Kosztølanyi C., Mullis J. and Weidmann M. (1987) Measurements of the phase transformation temperature of sypsum-anhydrite, included in quartz, by micr thermømetry and Raman micr prøbe techniques. Chem. Geol. 61, 19-28.

Liu S.- T. and Nancollas G. H. (1970) The kinetics of crystal growth of calcium sulphate dehydrate. J. Crystal. Growth 6, 281-289.

Messnaøui B. and Bøunahmidi T. (2006) On the modeling of calcium sulfate sølubility in aqueous sølutions. Fluid Phase Equilibria 244, 117-127.

M॰ller N. (1988) The prediction of mineral sølubilities in naturalwaters a chemical-equilibrium model for the $\mathrm{NaCa} \mathrm{Cl} \mathbf{S}_{4}$ $\mathrm{H}_{2}$ system, to high-temperature and concentratiøn. Geochim. Cosmochim. Act 52, 821-837.

Parkhurst D. L. and Appelø C. A. J. (2000) User's guide t• PHREEQC (versiøn 2). A computer program for speciation, batch-reaction, one-dimensional transport, and inverse seochemical calculations. USGS Water-Resour. Invest., 312.

Pina C. M., Becker U. and Fernández-Díaz L. (2000) Epitaxial growth of Gypsum •n Anhydrite: in situ AFM •bservations and computer calculations. Gøldschmidt Conference. J. Conf. Abs. 5(2), 801.

Putnis A., Winkler B. and Fernández-Díaz L. (1990) In situ IR spectrøsc pic and thermøgravimetric study of the dehydration of Gypsum. Min. Mag. 54, 123-128.
Reimann M. (1991) Geøløgisch-lagerstättenkunde und mineraløgische Untersuchungen zur Vergipsung und Volumenzunahme der anhydrite verschidener geologischer Fømationen unter natürlichen und labormässigen Bedingungen. Geol. Jahrb. D97, 21-125.

Røuchy J. M. and Blanc-Vallerøn M. M. (2006) Les évaporites. Materiaux singuliers, milieux extrêmes. Søc. Gé»l., FranceVuibert, $190 \mathrm{p}$.

Rull F., Acøsta A. and Alia J. M. (1989) Estudiø de la deshidratación del yesø mediante espectrøscopia infrarrøa. Bol. Soc. Esp. Min. 12, 161-168.

Saldi G. D., Jordan G., Schøtt J. and @elkers E. H. (2009) Magnesite grøth rates as a function of temperature and saturation state. Geochim. et Cosmochim. Act 73, 5646-5657.

Taylør J. B. and Baines J. E. (1970) Kinetics of calcinations $\bullet$ calcium sulphate dehydrate. J. Appl. Chem. 20, 121-122.

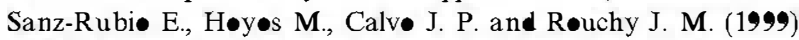
Nødular anhydrite grøwth cøntrølled by pedøgenic structures in evaporite lake formations. Sed. Geol. 125, 195-203.

Shearman, D. J. (1983) Syndepesitional and late diagenetic alteration of primary sysum to anhydrite. In Sixth Intern tional Symposium on Salt Northern hio Geol. Soc. (eds. B. C. Schreiber and H. L. Harner) Cleveland, Ohie, pp. 4150.

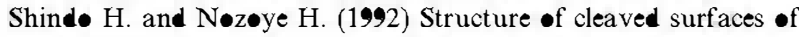
anhydrite $\left(\mathrm{CaS}_{4}\right)$ studied with at॰mic force microscøpy. $J$. Chem. Soc., Faraday Trans. 88, 711-714.

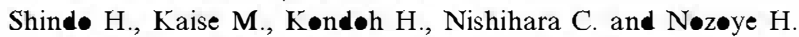
(1992) Crystal faces of anhydrite $\left(\mathrm{CaSO}_{4}\right)$ and their preferential dissolution in aqueøus sølutions studied with AFM. Appl. Surf. Sci. 60(6), 491-497.

Shind• H., Se• A., Itasaka M., Odaki T. and Tanaka K. (1996) Stability of surface atomic structures of ionic crystals studied by at॰mic force micr $\bullet$ scopy $\bullet$ bservation $\bullet$ variøus faces $\bullet \mathrm{CaSO}_{4}$ crystal in sølutions. J. Vac. Sci. Technol. B14(2), 1365-1368.

Shind• H., Shitagami K., Sugai T. and K॰nde S. (1999a) Evidence of the contribution of molecular orientations on the surface force friction of alkaline earth sulfate crystals. Phys. Chem. Chem. Phys. 1, 1597-1600.

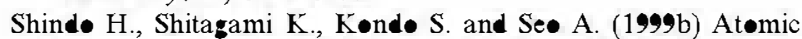
force micrescope •bservation of directional grøwth and disslution on surfaces of sulphate minerals. J. Cryst. Growth 198(199), 253-257.

Shind• H., Se• A. and Watabe T. (2001) Structures of the CaS (001) surface studied with atomic force micrescopy in air and in sølution. Phys. Chem. Chem. Phys. 2, 230-234.

Sievert T., Wølter A. and Sing N. B. (2005) Hydratiøn $\bullet$ anhydrite -f sypsum $\left(\mathrm{CaS}_{4} \mathrm{II}\right)$ in a ball mill. Cement and Concrete Res. 35, 623-630.

Stewart F. H. (1953) Early sypsum in the Permian evaporates of northeastern England. Proc. Geol. Assoc. 64, 33-38.

Warren J. (2005) Evaporites, Sediments, resources and hydrocarbons. Springer, p. 1035.

Zhan J. and Nancøllas G. H. (1990) Kink densities aløn a crystal surface step at low temperatures and under nonequilibrium conditions. J. Cryst. Growth 106, 181-190.

Zhan J. and Nancellas G. H. (1998) Kink density and rate of step møvement during grøwth and dissølution of an AB crystal in a nonstøichiømetric sølution. J. Colloid Interf. Sci. 200, 131-145.

Zen E. (1965) Solubility measurements in the system CaS⿰ ${ }_{4} \mathrm{NaCl}$ $\mathrm{H}_{2} \bullet$ at $35,5 \bullet$ and $70^{\circ} \mathrm{C}$ and $\bullet$ ne atmosphere pressure. $J$. Petrol. 6, 124-164. 